\title{
Exclusive breastfeeding practice and associated factors among first time mothers in Bahir Dar city, North West Ethiopia, 2016: A cross sectional study.
}

Tilksew Abitie Ayalew ( $\sim$ jonnyayu@gmail.com )

\section{Research}

Keywords: Exclusive breastfeeding, First time mothers, Prevalence, Bahir Dar, Ethiopia

Posted Date: December 10th, 2019

DOI: https://doi.org/10.21203/rs.2.18525/v1

License: @ (i) This work is licensed under a Creative Commons Attribution 4.0 International License. Read Full License 


\section{Abstract}

Background: Exclusive breastfeeding means infants were fed only breast milk, not even water, one day (24 hrs.) before the survey was conducted. It is considered as core practice to achieve almost all 2030 Sustainable Development Goals, specifically sustainable development goal 2 which focuses in ending hunger and improving nutrition and goal 3 which focuses in reducing child and maternal mortality. The objective of this study was to assess the prevalence of exclusive breastfeeding practice and its associated factor among first time mothers in Bahir Dar city, North West Ethiopia.

Method: A community based quantitative cross sectional study was carried out from March to April, 2016 among 423 first time mothers in Bahir Dar city. Study participants were selected by busing simple random sampling method i.e., lottery method. Data on infant feeding practice were collected by trained interviewers who used a structured questionnaire. Both binary and multivariable logistic regression were used to determine factors associated with exclusive breastfeeding. Statistical significance was declared at $\mathrm{P}$-value $<0.05$.

Results: Prevalence of exclusive breastfeeding practice 24 hours before the survey was $57.3 \%(95 \% \mathrm{CL}: 52.3 \%, 62 \%)$. Mothers not being married (AOR 2.787,95 \% Cl: 1.083, 7.171), were supported by their husband (AOR 3.658, 95\%Cl: 2.132, 6.278), with no breast complication (AOR 3.658, 95\% Cl: 2.132, 6.278), who had four or more antenatal care follow up (AOR $2.512,95 \% \mathrm{Cl}: 1.494,4.233)$ were more likely to practice exclusive breastfeeding. On the other hand, mothers who were living in nuclear family (AOR $0.48,95 \% \mathrm{Cl}: 0.231,1.001)$ were less likely to practice exclusive breastfeeding.

Conclusion: The prevalence of exclusive breastfeeding practice in the study area was lower than the national recommended level. In this study maternal age, number of antenatal care visits, husband support, breast complication and type of family were predictors of exclusive breastfeeding. Involving partners during infant feeding counseling and education, creating awareness about breastfeeding, special attention for the first time mothers, and prenatal education for expectant parents were recommended to improve exclusive breastfeeding among first time mothers.

\section{Background}

Breastfeeding is unparalleled in providing the ideal food for infants. It contains all necessary nutrients for growth and development of infants and antibodies that can protect infants from many childhood illnesses [1]. WHO and UNICEF jointly recommended that breastfeeding should be initiated within one hour of delivery, exclusive breastfeeding for six months and continued breastfeeding with adequate and safe complementary feeding up to two years and beyond [2-4].According to the 2016 Lancet Series on breastfeeding [5] 823,000 child deaths and 20,000 maternal deaths could be averted through universal breastfeeding each year. A meta-analysis by Sankar et al. showed the risk of all-cause mortality for not breastfed infants was 14.4 times higher compared to exclusive breastfed infants0-5 months of age[6].

Exclusive breastfeeding is known to be the single most important preventive intervention for reducing early childhood mortality. It has the potential to reduce mortality among under- 5 children by $19 \%$ together with appropriate complementary feeding [7]. Breastfeeding is a critical intervention to reduce under five child mortality. Death of more than 820,000 under five children in which $87 \%$ of them are infants less than 6 months of age could be averted annually in 75 LMICs by increasing breastfeeding every year. In children aged 6-23 months, any breastfeeding was associated with a 50\% reduction in deaths[2].

Breastfeeding has numerous benefits for infants, mothers and the world community at large. Reducing overall infant mortality, preventing malnutrition, decreasing chronic conditions such as asthma, over weight and obesity, cardiovascular diseases, childhood cancers and breast cancer in later life are among infants' benefits of breastfeeding. It has also benefits for nursing mothers in reducing bleeding, breast cancer and ovarian cancer $[8,9]$. 
Breastfeeding also is a vital element of global socioeconomic development efforts to create healthiest, prosperous and sustainable globe. It adds around \$US 300 billion to the world economy [10]. It has also a great contribution to keep environmental sustainability. Breast milk is a "natural, renewable food" that is environmentally sound and produced and delivered to the consumer without pollution, unnecessary packaging or waste. Breast milk's contribution to more environmentally-responsible production and consumption patterns makes it an invaluable resource in reaching global sustainability and climate change goals[2]. Although these multitude benefits of breastfeeding, analysis of data from 123 countries shows that around the world, $4 \%$ of babies in low- and middle-income countries and $21 \%$ of babies in highincome countries are never breastfed respectively[4].

Many factors were found to affect exclusive breastfeeding such as; age of mothers, household income, marital status, sex and age of infant, cultural practices, lack of adequate support in health facilities, aggressive promotion of infant formula through media, lack of knowledge on dangers of artificial feeding among mothers, their partners and community $[1,8,11$, 12].

Ethiopian HSDP IV had planned to increase the proportion of exclusive breastfeeding to 70\% by the end of 2015 [13].But the current Ethiopian Health and Demographic Health Survey (EDHS 2016) estimated only 58\% of infants were exclusively breastfed [14].

Exclusive breastfeeding is considered as core practice to achieve a 2030 sustainable development agendas, specifically SDG 2-which focuses in ending hunger and improving nutrition worldwide;SDG3-which focuses in reducing child and maternal mortality and improving health for all people globally [10, 15].

Although considerable evidence on the health and economy benefits of breastfeeding, the vast majority of children are not breastfed according to the World Health Organization's recommendation. In 2018,163 of 194 countries (84\%) lag behind to meet the global target, which aims to increase the proportion of exclusively breastfeeding at six months to $50 \%$ by 2025 . This low prevalence of exclusive breastfeeding has real and lasting consequences in terms of human life, quality of life, and national economic outcomes [16].

Although the several established benefits of breastfeeding, formula feeding has also gained a lot of recognition among first-time mothers. First-time mothers might have several perceptions about breastfeeding based on what they have seen or heard from people about breastfeeding. Most of them might feel unskilled to practice breastfeeding [17].

Despite a number of studies are done on the practice of exclusive breastfeeding and associated factors in Ethiopia, no single study was done which shows the magnitude and associated factors for the first time mothers. Therefore the purpose of this study was to assess exclusive breastfeeding and associated factors among first time mothers with infants less than six months old in Bahir Dar City, North West Ethiopia.

\section{Methods And Materials}

\section{Study setting and participants}

A community based cross sectional study was carried out from March to April, 2016. The study was conducted in Bahir Dar city which is located in Amhara National Regional State, Ethiopia. It is situated on the southern shore of Lake Tana, the source of the Blue Nile. The city is located approximately 578 kilometers northwest of Addis Ababa, the capital city of Ethiopia. Based on the 2007 Census conducted by the Central Statistical Agency of Ethiopia, the city has a total population of 221,991 , of whom $49 \%$ are men and $51 \%$ are women. From female population around $66 \%$ are reproductive age groups. The city has nine administrative sub cities. Regarding to health care delivery system; the city has one governmental specialized referral hospital, one governmental general hospital, two private hospitals, ten health centers, and a number of specialized private clinics, pharmacies and drug stores which give services for the population of the city[18, 19]. 


\section{Sample size and sampling technique}

The sample size was calculated using single population proportion formula by considering the following assumptions; $\mathrm{P}=50 \%$; there is no known prevalence done in Ethiopia for first time mothers, level of confidence $=95 \%$, margin of error (d) $=5 \%$. By considering $10 \%$ non-response the final sample size was 423 .

All of the nine sub cities of Bahir Dar which are called (Tana, Belay Zeleke, Hidar11, Fasilo, Gingot20, Gish Abay, Shumabo, Shimbt, and Sefeneselam) in local language were included in the study to get adequate sample of first time mothers. The total sample size was proportionally allocated to size to select study participants from each sub city. Finally each participant was selected by using simple random sampling technique i.e., a lottery method was used. The registration of mothers who have a child less than six months was obtained from local health extension workers record folder and was used to get the list of children of first time mothers in each sub city. The actual age of the infant was determined by asking the mother and reviewing the birth certificate card.

\section{Measurement}

A structured interviewer administered questionnaire was used to collect data from participants of the study. The questionnaire was constructed by adopting and modifying from Ethiopian Demographic Health Survey (EDHS) [20] and other studies previously done on similar topic [21-23]. A 24 hours recall infant diet method was used to determine the practice of exclusive breastfeeding. First, the English version of the questionnaire was prepared. Then it was translated to Amharic version (local language) and translated back to English to check its consistency and accuracy. The questionnaire included sociodemographic characteristics such as age, marital status, ethnicity and religion. Items to assess maternal health care service utilization, breastfeeding related practices, breastfeeding information and knowledge were also included. In addition to these, the tool contains items for assessing barriers and supporting system of exclusive breastfeeding. Three diploma nurses and two Bachelor of Science nurses were recruited as data collectors and supervisors respectively. In order to ensure data quality, training was given for supervisors and data collectors for two consecutive days on the overall content of questionnaire, how to approach participants and data collection process.

\section{Operational definitions}

Exclusive breastfeeding: If an infant was fed only breast milk (with the exception ordered medicines and vitamins by health professionals) one day (24 hrs.) before the survey was conducted [12, 21].

Predominant breastfeeding: If an infant mainly took breast milk with non-milk liquid foods such as plain water, tea, salt/sugar solution and juices one day (24 hrs.) before the survey was conducted [12, 21].

Mixed breastfeeding: If an infant was fed breast milk with addition of liquid foods like cow milk and formula milk and soft foods like mashed potatoes/meat, porridge, egg, butter one day (24 hrs.) before the survey was conducted [21].

Exclusive replacement feeding: If an infant was fed other foods without breast milk one day ( $24 \mathrm{hrs}$.) before the survey was conducted [21].

First time mother: A mother who gives a birth for the first time[17].

Husband support: Husband who supports, encourages and promotes the mother's breastfeeding practice[24].

\section{Statistical analysis}

The collected data were checked manually by supervisors and the principal investigator for its completeness and consistency. Then, it was coded and entered into EPI Info version 3.5.3 and transferred to SPSS version 20 for analysis. Descriptive statistics was used to summarize the socio-demographic characteristics' of the study participants and the 
prevalence of exclusive breastfeeding. To identify factors associated with exclusive breastfeeding practice, binary logistic regression analysis was performed at two levels. First bivariate logistic regression was performed to each independent variable with the independent variable and those variables with a p value $<0.25$ were included in the final model (multivariable analysis). Strength of association was measured using odds ratio, and $95 \%$ confidence intervals. Statistical significance was declared at $P$ value $<0.05$.

\section{Results}

\section{Sociodemographic characteristics}

All participants in this study were first time mothers living in Bahir Dar city. From423 eligible first time mothers, 400 were interviewed in this study which made the response rate $95.0 \%$. The mean age of mothers was 26 years with standard deviation of $(S D \pm 4.08)$. More than half of participants (52.2\%) were between the age of fifteen and twenty years old. More than two third of mothers were from Orthodox Christianity religion. Majority of study participants (87.3\%) were from Amhara ethnic group. Regarding to educational status around one third of mothers (33\%) were not educated at all while another one third of mothers (31.5\%) were educated at college and above levels. The average household income of respondents who disclosed their household income was 3762 Ethiopian birr per month with standard deviation $(\mathrm{SD} \pm 2136.48)$ (Table 1).

\section{Maternal and infant health service utilization characteristics}

Almost half of infants (53.5\%) were male babies. More than half of infants were aged between 0-90 days. Majority of mothers (90.8\%) attended antenatal care follow up and majority of mothers $(60.2 \%)$ attended in health center. On the other hand, only one hundred thirty three (36.6\%) attended more than three antenatal care visits. More than two third of mothers (76.3\%) received breastfeeding counseling during their antenatal care visits. Regarding to delivery, majority (93.8\%) of mothers delivered in health institution and majority $329(82.2 \%)$ of mothers were delivered by normal/spontaneous vaginal delivery (Table2).

\section{Exclusive breastfeeding and related practices}

Prevalence of exclusive breastfeeding practice a day (24hrs.) before the survey was $57.3 \%$ (95\%CL: 52.3\%, 62\%).Among first time mothers who did not exclusively breastfeed, seventy two (18.3\%) gave mixed feeding, sixty one (15.3\%) gave predominant breastfeeding and thirty eight (9.5\%) gave formula feeding to their infant. Majority (91.2\%) of mothers gave colostrum to their infant. Among mothers who did not practice exclusively breast feeding, the main reasons mentioned were; lack of information about exclusive breastfeeding 133(33.8\%), lack of time due to work demand 101(25.3\%), insufficient breastfeeding 72(18\%), breast complication 55 (13.5\%) and maternal illness 37 (9.3\%) (Table3).

\section{Information, knowledge, barriers and supporting systems of exclusive breastfeeding}

Regarding to knowledge and information about breastfeeding 316(79\%) mothers were found to have adequate knowledge about breastfeeding while 344(86\%) were informed about breastfeeding. For mothers who were informed about breastfeeding the main source of information mentioned were: television (49.5\%), radio (20.3\%), health extension workers (20\%), volunteer health workers (5\%) and friends/relatives (5.3\%).Concerning breast problem, around two third of mothers (51.5\%) faced some type of breast problem. Among mothers faced breast problems, the main problems faced were: mastitis (41.4\%), abscess (32.9\%) and sore/cracked nipples (25.7).Regarding to supporting system of mothers in infant care and breastfeeding, around 357(89.5\%) were supported by their husband. Among employed mothers, less than half (44.5\%) were supported by their organization .On the other hand, few mothers (13\%) had got support from cultural system of their community (Table 4).

\section{Factors associated with exclusive breastfeeding practice}


First binary logistic regression analysis was carried out to select variables having association with EBF practice. Then, eight variables were retained for final model analysis. Sex of infant, maternal age, number of antenatal care visits, and husband support, informational status, breast problems and type of family were the independent predictors of exclusive breastfeeding.

From these independent predictors; current marital status, number of ANC visits, husband support, breast problem and type of family were significantly associated with exclusive breastfeeding practice in multivariable logistic regression analysis.

Husband support was significantly associated with exclusive breastfeeding practice. Mothers who were supported by their husband were more likely to practice exclusive breastfeeding (AOR 3.658, 95\% Cl: $2.132,6.278$ ) than their counter parts. Similarly, breast problem was significantly associated with exclusive breastfeeding. Mothers who did not face breast problems were more likely to practice exclusive breastfeeding (AOR 3.658, 95\% Cl: $2.132,6.278$ ) than mothers who faced breast problems. At the same time, current marital status was significantly associated with exclusive breastfeeding practice. Women who are not currently married were almost three times more likely to practice exclusive breastfeeding (AOR: $2.787,95 \% \mathrm{Cl} 1.083,7.171$ ) than their counter parts.

Mothers who had four or more antenatal care follow up visits were almost 2.5 times more likely to feed breast milk their infants exclusively (AOR 2.512, 95\% Cl: 1.494, 4.233) than mothers who had less than three antenatal care follow up visits. In the same way, type of family was associated with exclusive breastfeeding practice. Mothers who had nuclear family were less likely almost by half to practice exclusive breastfeeding (AOR $0.48,95 \% \mathrm{Cl}: 0.231,1.001)$ than mothers who had extended family (Table 5).

\section{Discussion}

Although the health benefit of breastfeeding for mothers and children is well known, the prevalence of exclusive breastfeeding was low in the current study area. The prevalence of exclusive breastfeeding in this study area preceding $24 \mathrm{hrs}$ of the survey was $57.3 \%$ (95\% CL: $52.3 \%, 62 \%)$. The result was higher than the current global prevalence (40\%) but far lower than the 2030 target (70\%) [25]. The result was consistent with the national prevalence from 2016 EDHS 58\% [14]. It is also relatively consistent with studies conducted in; Motta town, Ethiopia 50.1\%[21], Gahanna 64\% [26], Debremarkos, Ethiopia 60.8\% [27], Ecuador 62.8\% [28] and Hawassa, Ethiopia 60.9\% [29]. On the other hand, the result was higher than the studies done in; Saudi Arabia 0.8-43.9\% [30], Nigeria 33.5\% [31], Papua New Guinea 17\% [32], Democratic Republic Congo 39\% [33], Addis Ababa, Ethiopia 29.3\% [34] and North West Ethiopia30.7\%[35].However, the result was lower than studies conducted in; Debre Birhan, Ethiopia 68.6\% [11],Afar, Ethiopia 81.1\% [36], Tigray Ethiopia70.2\% [37].The difference could be due to methodological variation between studies and differences in socio-cultural and socio-economic dissimilarities between mother infant dyad and other differences like health care service utilization between the current study population and referenced population.

In the current study marital status was significantly associated with exclusive breastfeeding. Unexpectedly, mothers who are not currently married were more likely to practice exclusive breastfeeding. The result is similar with a study done in Ethiopia[12].The explanation behind might be mothers who are not married could not be influenced by their mother in law to give other feedings to their infants. This might also be that according to Ethiopian culture, most first time mothers are under the care of their family. This might help them get support from their family to practice exclusive breastfeeding. A study from Kenya[38] confirmed that family support is a key factor in the success of exclusive breastfeeding. Otherwise the result is dissimilar with studies done in; North west Ethiopia [35],Ghana[39] and Democratic Republic Congo[40] in which married women were more likely to practice exclusive breastfeeding than mothers who are not married. The difference could be due to methodological variation and different sociodemographic characteristics of study population between the current study and the previous studies. 
The current study indicated that mothers who had more frequent antenatal care visits $(\geq 4)$ were more likely to practice exclusive breastfeeding. The finding is consistent with studies carried out in; Nigeria[41] and Malawi [42]. The finding highlights mothers who have more frequent antenatal care follow up could get adequate breastfeeding counselling and could have knowledge about the importance of exclusive breastfeeding. Actually, antenatal care visit is an entry point to improve mothers' breastfeeding behavior by providing nutritional counseling and education. It is also evident that antenatal breastfeeding counseling significantly improves EBF practice [43].Although it has been proven that antenatal breast feeding counselling enhances breastfeeding practice in previous studies [21, 34],it was not associated with exclusive breastfeeding in the current study.

On the other hand, this study indicated that husband support was positively associated with exclusive breastfeeding practice. The finding is in line with the study conducted in Motta, Ethiopia[21],United Kingdom [24] and Nepal [44]. The study in Nepal [44] revealed that mothers who got support from their husbands were 10 times significantly more likely to practice exclusive breastfeeding. The possible explanation might be due to husband plays important role in the decision making about family and household affairs and which affects many aspects of family life including infant feeding practices. Husbands' participation in breastfeeding can be a strong approach for encouraging women to breastfeed and continue breastfeeding for longer time duration. Mannion et al.[45] showed that mothers feel more capable and confident about breastfeeding when they perceive their partners are supportive by way of verbal encouragement and active involvement in breastfeeding activities. Nepali et al[44] also showed that husbands' support in terms of coping with breastfeeding challenges, encouraging to breastfeed, assisting in breastfeeding activities are essential to boost up the mother's breastfeeding skills.

This study also revealed that mothers without breast complication were more likely to practice exclusive breastfeeding than mothers who had any of the breast problems. The finding is similar with the study done in; Hawassa, Ethiopia[29], Zagazig, Egypt[46]. This might because absence of breast complications like engorgement, nipple pain or sore nipple, mastitis and nipple abscess might facilitate success in exclusive breastfeeding practice. On the other hand, when mothers face breast problem; they could give other feedings like cow milk and formula milk to maintain nutritional need of the infant. Studies revealed that persistent nipple complication is one of the most common reasons given by mothers for ceasing exclusive breastfeeding[47].

Family structure had an association with exclusive breastfeeding. A mother living in nuclear family was less likely to practice exclusive breast feeding. The finding is in parallel with the study done in rural Indian mothers [48] in which mothers from nuclear family had high risk of cessation of exclusive breastfeeding than mothers from joint family. This might be because mothers from nuclear family lack support from members of extended family. When mothers get support from members of family they could have better time and energy to practice exclusive breastfeeding. On the other hand, Nyanga NM et al[38] revealed that family support is a key factor in the success of exclusive breastfeeding with special focus on partner involvement.

\section{Conclusion}

The prevalence of exclusive breastfeeding in the study area is consistent with the national prevalence from 2016 EDHS, higher than the current global prevalence and far lower than the 2030 target of exclusive breast feeding. The independent predictors of exclusive breastfeeding in the current study were; maternal age, number of antenatal care visits, husband support, breast complication and type of family. Recommendations forwarded to improve exclusive breastfeeding were; involving partners during infant feeding counseling and education, creating awareness about the benefits of breastfeeding for the baby and the mother to family members and the whole community. In addition to these, health care professionals should give special attention for the first time mothers since they don't have previous experience of breastfeeding. Moreover, the government of Ethiopia should make arrangements for prenatal education for expectant mothers and fathers specifically for the first time parents. 


\section{Declarations}

Ethics approval: Ethical approval was obtained from the research review ethical committee of the Addis Ababa University, and permission letter was obtained from Amhara regional health office. The data collectors informed each respondent about the study and verbal consent to participate was obtained from mothers of the child. Verbal consent was obtained from each study participants and confidentiality was assured for all the information provided. Moreover, personal identifiers were not being included on questionnaire.

Consent for publication: Not applicable

Availability of data and material: The data of this study can't be shared publically due to presence of sensitive (confidential) participants' information.

Competing interests: The author declared that there is no any competing interest.

Funding: This study received financial support for data collection from the Addis Ababa University.

Authors' contributions: The author TA contributed to the design of this study. The author conceived and designed the study, analyzed and interpreted data; drafted the manuscript for important intellectual content. TA reviewed and revised the draft further and approved the final version for submission.

Acknowledgement: The author would like to thank librarian staffs, study participants, data collectors and supervisors for their cooperation during the entire work.

\section{Abbreviations}

AOR

Adjusted Odds Ratio

ANC

Antenatal Care

$\mathrm{CL}$

Confidence Level

COR

Crude Odds Ratio

EDHS

Ethiopian Demographic Health Survey

HSDP

Health Sector Development Program

SD

Standard Deviation

SDG

Sustainable Development Goal

WHO

World Health Organization

\section{References}

1. WHO, The International Code of Marketing of Breast-milk Substitutes: Frequently Asked Questions (2017 Update), Geneva, Switzerland, World Health Organization; 2017. Licence: CC BY-NC-SA 3.0 IGO. 
2. WHO, BREASTFEEDING IN THE 21ST CENTURY;Word Health Organizationavailable at https://www.who.int/pmnch/media/news/2016/breastfeeding_brief., 2016.

3. WHO, Implementation guidance: protecting, promoting and supporting breastfeeding in facilities providing maternity and newborn services - the revised Baby-friendly Hospital Initiative. Geneva: World HealthOrganization; 2018. Licence: CC BY-NC-SA 3.0 IGO.

4. UNICEF, Breastfeeding:A Mothers Gift for Every Child.Avaiable at https://www.unicef.org/publications/index_102824.html. , 2018, UNICEF. p. 16.

5. The Lancet, the lancet series on breastfeeding;www.thelancet.com. 2016. vol387.

6. Sankar and et al, Optimal Breastfeeding Practices and Infant and Child Mortality- A Systematic Review and Metaanalysis. Acta Pædiatrica, 2015.

7. WHO, WHA Global Nutrition Targets 2025: Breastfeeding Policy Brief:Geneva;World Health Organization, 2014.

8. UNICEF, Improving Exclusive Breastfeeding Practices by using Communication for Development in Infant and Young Child Feeding Programmes, 2010.

9. UNICEF, Final IYCF programming guide ,Nutrition Section, Programmes, UNICEF New York: avaiable, at: iycn@unicef.org, 2011.

10. UNICEF, Breastfeeding and the Sustainable Development Goals Factsheet:unicef:2016.

11. Asfaw, M.M., M.D. Argaw, and Z.K. Kefene, Factors associated with exclusive breastfeeding practices in Debre Berhan District, Central Ethiopia: a cross sectional community based study. International Breastfeeding Journal, 2015. 10(1).

12. tewodros Alemayehu, Jemal Haidar, and Derje Habte, Determinants $f$ exclusive breastfeeding practices in Ethiopia. Ethiop.J.Health Dev. , 2009. 23(1): p. 12-18.

13. Federal Ministry of Ethiopia, Health Sector Development Program IV(2010/11-2014/15), 2010.

14. Central Statistical Agency (CSA) [Ethiopia] and ICF. 2016. Ethiopia Demographic and Health Survey 2016: Key Indicators Report. Addis Ababa, Ethiopia, and Rockville, Maryland, USA. CSA and ICF.

15. Shingirai M Katsinde and Sunitha C Srinivas, Breast feeding and The Sustainable Development agenda. Indian Journal of Pharmacy Practice, 2016. 9(3).

16. Alive \&Thrive, "The cost of not breastfeeding: global results from a new tool", published in Health Policy and Planning in June 2019.

17. Intiful F. and et al:, Views of First-Time Expectant Mothers on Breastfeeding:A Study in Three Health Facilities in Accra, Ghana. Hindawi ,Advances in Public Health, 2017: p. 6.

18. Fedral Democratic Republic of Ethiopia, Census Commission.Summary and Statistical Report of the 2007 Population and Housing Census. (The Ethiopian statistical agency Bereau, Addis Ababa, 2008).

19. Bahir Dar city adminstration.population census of Bahir Dar city. (Bahir Dar city administration, Bahir Dar, 2016).

20. Central Statistical Agency, Ethiopia Demographic and Health Survey 2011.Addia Ababa, Ethiopia. , 2012, ICF International: Calverton, Maryland.

21. Tewabe, T. and et al., Exclusive breastfeeding practice and associated factors among mothers in Motta town, East Gojjam zone, Amhara Regional State, Ethiopia, 2015: a cross-sectional study. International Breastfeeding Journal, 2017. 2:12.

22. Mussie A . and et al, Factors Associated with Timely Initiation and Exclusive Breast Feeding among Mothers of Axum Town, Northern Ethiopia. . Science Journal of PublicHealth, 2014. 2(5): p. 394-401.

23. Tori Sutherland, et al., Breastfeeding Practices Among First-Time Mothers and Across Multiple Pregnancies. Maternal and Child Health Journal, 2013.

24. Brown, A., and, and R. Davies, Fathers' experiences of supporting breastfeeding: challenges for breastfeeding promotion and education. Maternal and child Nutrition, 2014. 10: p. 510-526. 
25. UNICEF, BREASTFEEDING AND FAMILY-FRIENDLY POLICIES An evidence brief, 2019.

26. Tampah-Naah and Kumi-Kyereme, Determinants of exclusive breastfeeding among mothers in Ghana: a crosssectional study. International Breastfeeding Journal, 2013. 8(13).

27. Mekuria, G. and M. Edris, Exclusive breastfeeding and associated factors among mothers in Debre Markos, Northwest Ethiopia: a cross-sectional study. Int Breastfeed J, 2015. 10(1): p. 1.

28. Jara-Palacios, M.A., et al., Prevalence and determinants of exclusive breastfeeding among adolescent mothers from Quito, Ecuador: a cross-sectional study. Int Breastfeed J, 2015. 10: p. 33.

29. Adugna, B., et al., Determinants of exclusive breastfeeding in infants less than six months of age in Hawassa, an urban setting, Ethiopia. Int Breastfeed J, 2017. 12: p. 45.

30. Juaid, A. and et al, Breastfeeding in Saudi Arabia: a review. International Breastfeeding Journal, 2014. 9(1).

31. Onah and et al, Infant feeding practices and maternal socio-demographic factors that influence practice of exclusive breastfeeding among mothers inNnewi South-East Nigeria: a cross-sectional and analytical study. International Breastfeeding Journal 2014. 9(6).

32. Kuzma, Knowledge, attitude and practice related to infant feeding among women in rural Papua New Guinea: a descriptive, mixed method study. International Breastfeeding Journal, 2013. 8(16).

33. Yotebieng and et al, Infant feeding practices and determinants of poor breastfeeding behavior in Kinshasa, Democratic Republic of Congo: a descriptive study. International Breastfeeding Journal, 2013. 8(11).

34. Shifraw, T., A. Worku, and Y. Berhane, Factors associated exclusive breastfeeding practices of urban women in Addis Ababa public health centers, Ethiopia: a cross sectional study. Int Breastfeed J, 2015. 10: p. 22.

35. Biks, G.A., A. Tariku, and G.A. Tessema, Effects of antenatal care and institutional delivery on exclusive breastfeeding practice in northwest Ethiopia: a nested case-control study. Int Breastfeed J, 2015. 10: p. 30.

36. Liben, M.L., et al., Factors associated with exclusive breastfeeding practices among mothers in dubti town, afar regional state, northeast Ethiopia: a community based cross-sectional study. Int Breastfeed J, 2016. 11: p. 4.

37. Teka, B., H. Assefa, and K. Haileslassie, Prevalence and determinant factors of exclusive breastfeeding practices among mothers in Enderta woreda, Tigray, North Ethiopia: a cross-sectional study. Int Breastfeed J, 2015. 10(1): p. 2.

38. Nyanga NM and E. al, FACTORS INFLUENCING KNOWLEDGE AND PRACTICE OF EXCLUSIVE BREASTFEEDING IN NYANDO DISTRICT, KENYA. African Journal of Food,Agriculture,Nutrition and Development, 2012. 12(6).

39. Tampah-Naah, A.M. and A. Kumi-Kyereme, Determinants of exclusive breastfeeding among mothers in Ghana: a crosssectional study. Int Breastfeed J, 2013. 8(1): p. 13.

40. Dhakal, S., T.H. Lee, and E.W. Nam, Exclusive Breastfeeding Practice and Its Association among Mothers of under 5 Children in Kwango District, DR Congo. Int J Environ Res Public Health, 2017. 14(5).

41. Agho and et al, Determinants of exclusive breastfeeding in Nigeria. BMC Pregnancy and Childbirth, 2011. 11(2).

42. Chipojola, R., et al., Determinants of breastfeeding practices among mothers in Malawi: a population-based survey. Int Health, 2019.

43. Tariku, A., et al., Mothers' education and ANC visit improved exclusive breastfeeding in Dabat Health and Demographic Surveillance System Site, northwest Ethiopia. PLoS One, 2017. 12(6): p. e0179056.

44. Nepali and et al, Husbands' Support for Breastfeeding and Breastfeeding Self-Efficacy of Nepalese Mothers from Bungmati. Journal of Public Health, 2018. 18(I).

45. Mannion and et al, Maternal perceptions of partner support during breastfeeding. International Breastfeeding Journal 2013. 8(4).

46. Nahed Maher Ahmed Abdallah et al., Breast and Nipple Problems Encountered among Puerperal Primipara Women in Zagazig. International Journal of Pharmaceutical Research \&Allied Sciences, 2018. 7(1): p. 183-195.

Page $10 / 13$ 
47. Jacqueline , C. Kent, and E. al, Nipple Pain in Breastfeeding Mothers: Incidence, Causes and Treatments. International Journal of Environmental Research and Public Health, 2015.

48. MhiteRV and et al, Prevalence and determinant ofcessation of exclusive breastfeeding among primi-para rural Indian mothers. International Journal of Community medicine and Public Health, 2019. 6(1): p. 314-319.

\section{Tables}

Table1. Socio-demographic Characteristics of first time mothers with their infants aged less than six months old, in Bahirdar City, Amhara Regional, North west State Ethiopia, 2016.

\begin{tabular}{|c|c|c|c|}
\hline Variable & Category $(n=400)$ & Frequency & Percent (\%) \\
\hline \multirow{2}{*}{ Age of mother } & $15-29$ years & 209 & 52.2 \\
\hline & 30-49 years & 191 & 47.8 \\
\hline \multirow{3}{*}{ Religion } & Orthodox & 279 & 69 \\
\hline & Muslims & 95 & 23.7 \\
\hline & Others $^{1 *}$ & 29 & 7.3 \\
\hline \multirow[t]{3}{*}{ Ethnicity } & Amhara & 349 & 87.3 \\
\hline & Oromo & 33 & 8.3 \\
\hline & Others $^{2 *}$ & 18 & 4.4 \\
\hline \multirow[t]{4}{*}{ Educational Level of mother } & No formal education & 132 & 33 \\
\hline & Primary school(1-8) & 69 & 17.3 \\
\hline & Secondary school(9-12) & 73 & 18.3 \\
\hline & College and above & 126 & 31.5 \\
\hline \multirow[t]{2}{*}{ Occupation of mother } & employed & 295 & 73.8 \\
\hline & Unemployed & 105 & 26.2 \\
\hline Currently married & No & 54 & 13.5 \\
\hline \multirow{2}{*}{ Educational level of husband $(n=346)$} & Yes & 346 & 86.5 \\
\hline & Educate & 155 & 44.8 \\
\hline \multirow{3}{*}{ Husband occupation $(\mathrm{n}=346)$} & Uneducated & 191 & 55.2 \\
\hline & Employed & 185 & 53.5 \\
\hline & Unemployed & 161 & 46.5 \\
\hline \multirow[t]{2}{*}{ Type of family } & Nuclear & 325 & 81.2 \\
\hline & Extended & 75 & 18.8 \\
\hline \multirow[t]{3}{*}{ Household income } & $\leq 500$ birr & 3 & 0.8 \\
\hline & 501-1499 birr & 32 & 8 \\
\hline & $\geq 1500$ birr & 366 & 92.1 \\
\hline
\end{tabular}

Others $1 *=$ catholic, protestant, Jehovah; Others2*=Tigrie, Agew, gurage;

Table 2.Maternal and infant health service utilization characteristics of study participants in Bahidar City, Amhara Regional State, North West Ethiopia, 2016. 


\begin{tabular}{|l|l|l|l|}
\hline Variables & Category(400) & Frequency & Percent (\%) \\
\hline Sex of infant & Male & 214 & 53.5 \\
\hline Age of infant & Female & 186 & 46.5 \\
\hline & $0-90$ days & 210 & 52.5 \\
\hline & $91-120$ days & 99 & 24.8 \\
\hline ANC follow up & $121-150$ days & 39 & 9.7 \\
\hline \multirow{2}{*}{ Place of ANC } & $151-180$ days & 52 & 13 \\
\hline & Yes & 363 & 90.8 \\
\hline & No & 37 & 9.2 \\
\hline Number of ANC visits(n=363) & Hospital & 67 & 18.5 \\
\hline Breastfeeding counselling (ANC) & Health Centre & 222 & 61.2 \\
\hline & Private clinic & 74 & 24.4 \\
\hline Place of birth & Yes visits & 133 & 36.6 \\
\hline & No & 230 & 63.4 \\
\hline Mode of delivery & Health institution & 375 & 76.3 \\
\hline & Home & 25 & 93.8 \\
\hline & Normal/vaginal & 392 & 6.2 \\
\hline & Caesarian section & 71 & 82.2 \\
\hline
\end{tabular}

ANC: antenatal care

Table3.Breastfeeding related practices of first time mothers who have infants less than six months in Bahidar City, Amhara Regional State, North West Ethiopia, 2016.

\begin{tabular}{|l|l|l|l|}
\hline Variables & Category(n=400) & Frequency & $\begin{array}{l}\text { Percent } \\
(\%)\end{array}$ \\
\hline $\begin{array}{l}\text { Infant feeding practice 24hrs before the } \\
\text { survey }\end{array}$ & Exclusive breastfed & 299 & 57.3 \\
\hline & Predominant breastfed & 61 & 15.3 \\
\hline & Mixed feeding & 72 & 18.3 \\
\hline $\begin{array}{l}\text { Who influenced you to give feedings other } \\
\text { than breast milk }\end{array}$ & Formula feeding & My own decision & My husband \\
& My mother & 38 & 9.5 \\
& Mother in law & 92 & 24.6 \\
& Others a & 108 & 28.9 \\
\hline Colostrum feeding & Yes & 58 & 15.5 \\
\hline & No & 40 & 10.7 \\
\hline Reasons for not breastfed exclusively & Lack of information on exclusive & 365 & 91.2 \\
\hline & breastfeeding & 135 & 8.8 \\
\hline & Lack of time due to work demand & 101 & 33.8 \\
\hline & Insufficient breastfeeding & 72 & 25.3 \\
\hline & Breast problem/disorder & 55 & 18 \\
\hline & Maternal illness & 37 & 9.3 \\
\hline
\end{tabular}

$\mathrm{a}=$ Friends, neighbors, other members of extended family

Table4.Information, knowledge, barriers and supporting systems of exclusive breastfeeding practice among first time mothers who have infants less than six months in Bahidar City, Amhara Regional State, North West Ethiopia, 2016. 


\begin{tabular}{|l|l|l|l|}
\hline Variables & Responses & Frequency & Percent (\%) \\
\hline Informational status & Informed & 344 & 86 \\
\hline Source of information & Not informed & 56 & 14 \\
\hline & Television & 198 & 49.5 \\
\hline & Radio & 81 & 20.3 \\
\hline & Health extension workers & 80 & 20 \\
\hline & Volunteer health workers & 20 & 5 \\
\hline Knowledge about breastfeeding & Friends and relatives & 21 & 5.3 \\
\hline & Knowledgeable & 316 & 79 \\
\hline Any breast complication & Not Knowledgeable & 84 & 21 \\
\hline \multirow{2}{*}{ Type of complication } & No & 194 & 48.5 \\
\hline & Yes & 206 & 51.5 \\
\hline Management of complication & Abscess & 12 & 32.9 \\
\hline & Mastitis & 28 & 41.4 \\
\hline Husband support & Sore/cracked nipples & 9 & 25.7 \\
\hline & Others1* & 169 & 42.2 \\
\hline Religious father support & Yes & 231 & 57.8 \\
\hline Cultural support & No & 357 & 89.5 \\
\hline & Yes & 42 & 10.5 \\
\hline Organizational support & No & 165 & 41.3 \\
\hline & Yes & 235 & 58.7 \\
\hline & No & 52 & 13 \\
\hline & Yes & 348 & 87 \\
\hline & No & 171 & 45.5 \\
\hline
\end{tabular}

1 * express breast milk, rub local herbs on it.

Table5. Factors associated with exclusive breastfeeding among first time mothers having infants less than six months in Bahir Dar City, Amhara Regional State, North west Ethiopia, 2018.

\begin{tabular}{|c|c|c|c|c|c|}
\hline \multirow{3}{*}{ riable } & - & \multicolumn{2}{|c|}{$\begin{array}{l}- \\
\text { Exclusive breastfeeding }\end{array}$} & \multirow{2}{*}{ COR (95\%CL) } & \multirow[b]{2}{*}{ AOR (95\%CL) } \\
\hline & & Yes & No & & \\
\hline & & $(\mathrm{N} \& \%)$ & (N\& \%) & & \\
\hline \multirow[t]{2}{*}{$\mathrm{x}$ of infant } & Male & $166(77.6 \%)$ & $48(22.4 \%)$ & $2.135(1.380,3.304)$ & \\
\hline & Female & $115(61.8 \%)$ & $71(38.2 \%)$ & 1 & \\
\hline \multirow[t]{2}{*}{ iternal age } & $15-29$ & $139(66.5 \%)$ & $70(33.5 \%)$ & 1 & \\
\hline & $30-49$ & $142(74.3 \%)$ & $49(25.7 \%)$ & $1.459(0.946,2.251)$ & \\
\hline \multirow{2}{*}{$\begin{array}{l}\text { rrently } \\
\text { irried }\end{array}$} & No & $46(85.2 \%)$ & $8(14.8 \%)$ & $2.716(1.240,5.948)$ & $2.787(1.083,7.171)^{*}$ \\
\hline & Yes & $235(67.9 \%)$ & $111(32.1 \%)$ & 1 & 1 \\
\hline \multirow{2}{*}{$\begin{array}{l}\# \text { of ANC } \\
\text { low up }\end{array}$} & $\geq 4$ visits & $176(76.5 \%)$ & $54(23.5 \%)$ & $2.228(1.405,3.533)$ & $2.512(1.494,4.233) *$ \\
\hline & $<3$ visits & $79(59.4 \%)$ & $54(40.6 \%)$ & 1 & 1 \\
\hline \multirow{2}{*}{$\begin{array}{l}\text { sband } \\
\text { sport }\end{array}$} & Yes & $264(73.9 \%)$ & $93(26.1 \%)$ & $4.613(2.370,8.980)$ & $4.146(1.899,9.051)^{*}$ \\
\hline & No & $16(38.1 \%)$ & $26(61.9 \%)$ & 1 & 1 \\
\hline \multirow{2}{*}{$\begin{array}{l}\text { ormational } \\
\text { tus }\end{array}$} & Informed & $238(69.2 \%)$ & $106(30.8 \%)$ & 1 & \\
\hline & $\begin{array}{l}\text { Not } \\
\text { informed }\end{array}$ & $43(76.8 \%)$ & $13(23.2 \%)$ & $1.473(0.760,2.854)$ & \\
\hline \multirow{2}{*}{$\begin{array}{l}\text { east } \\
\text { jblem }\end{array}$} & No & $160(82.5 \%)$ & $34(17.5 \%)$ & $3.306(2.082,5.250)$ & $3.658(2.132,6.278)^{*}$ \\
\hline & Yes & $121(58.7 \%)$ & $85(41.3 \%)$ & 1 & 1 \\
\hline \multirow{2}{*}{$\begin{array}{l}\text { pe of } \\
\text { nily }\end{array}$} & Nuclear & $221(68.0 \%)$ & $104(32.0 \%)$ & $0.531(0.288,0.980)$ & $0.48(0.231,1.001)$ \\
\hline & Extended & $60(80.0 \%)$ & $15(20.0 \%)$ & 1 & 1 \\
\hline
\end{tabular}

*p-value < 0.05 (significant); \# =Number 